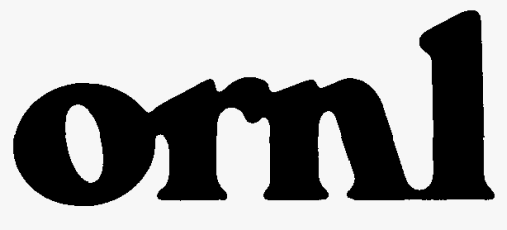

OAK RIDGE

NATIONAL

LABORATORY

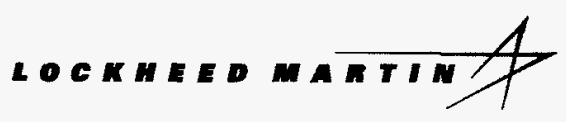

\section{Parking and Routing Information System Phase I Evaluation-Data Management and Quality Control/ Quality Assurance Plans}

Richard J. Carter

ORNL/TM-13361 
This report has been reproduced directly from the best available copy.

Available to DOE and DOE contractors from the Office of Scientific and Technical

Information, P.O.Box 62, Oak Pidge, TN 37831; prices available from (423) 576-8401, FTS 626-8401.

Available to the public from the National Technical Information Service, U.S. Department

of Commerce, 5285 Port Royal Rd., Springfield, VA 22161

This report was prepared a an account of work sponsored by an agency of the United States Govemment. Neither the United States Government nor any agency thereof, nor any of their employees, makes any warranty, express or implied, or assumes any legal liability or responsibility for the accuracy, completeness, or usefulness of any information, apparatus, product, or process disclosed, or represents that its use would not infringe privately owned rights. Reference herein to any specific commercial product, process, or service by trade name, trademark, manufacturer, or otherwise, does not necessarily constitute or imply its endorsement, recommendation, or favoring by the United States Government or any agency thereof. The view and opinions of authors expressed herein do not necessarily state or reflect those of the UnitedStatesGovernment or any agency thereot. 


\author{
Intelligent Transportation Systems \\ Johnson City, Tennessee
}

\title{
PARKING AND ROUTING INFORMATION SYSTEM PHASE I EVALUATION - DATA MANAGEMENT AND QUALITY CONTROL/QUALITY ASSURANCE PLANS
}

\author{
Richard J. Carter \\ Cognitive Systems and Human Factors Group \\ Intelligent Systems Section \\ Computer Science and Mathematics Division
}

Date Published: January 1997

Research sponsored by the

Federal Highway Administration,

State of Tennessee Department of Transportation, and the City of Johnson City, Tennessee under contract number ERD-95-1323

between Lockheed Martin Energy Research Corporation

and Raytheon Company in Bristol, Tennessee

Prepared by the

OAK RIDGE NATIONAL LABORATORY

Oak Ridge, Tennessee 37831 managed by

LOCKHEED MARTIN ENERGY RESEARCH CORPORATION

for the

DEPARTMENT OF ENERGY

under contract number DE-AC05-96OR22464 


\section{TABLE OF CONTENTS}

ABSTRACT …

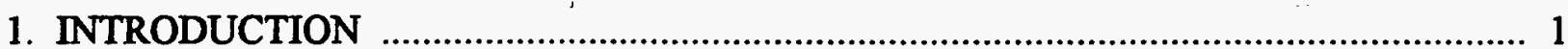

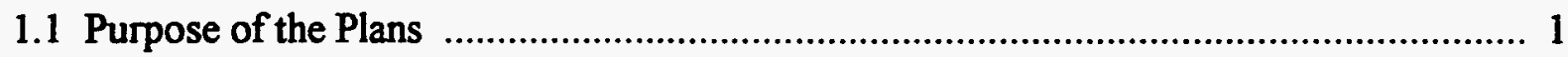

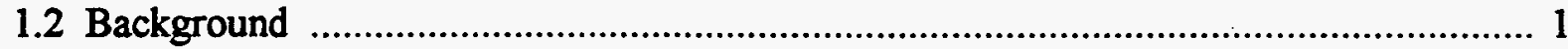

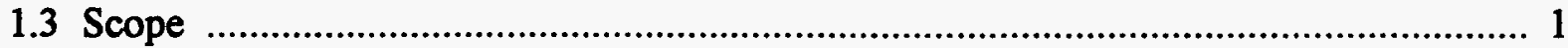

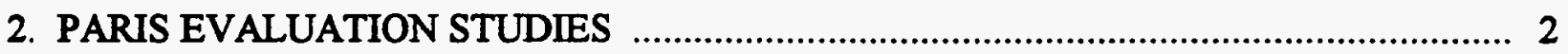

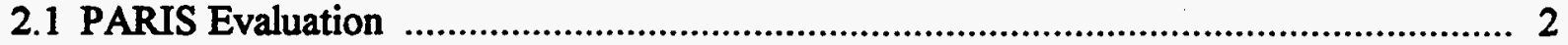

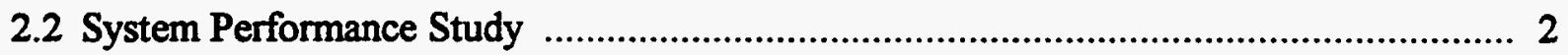

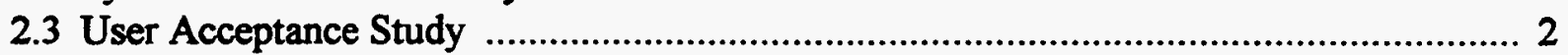

2.4 Institutional and Business Issues Study ................................................................... 2

2.5 Transportation Systems Study ............................................................................... 3

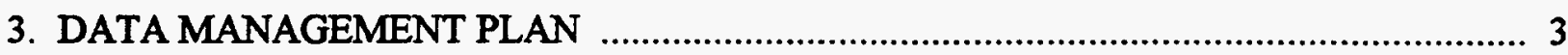

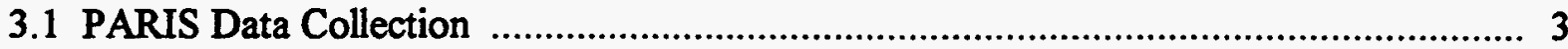

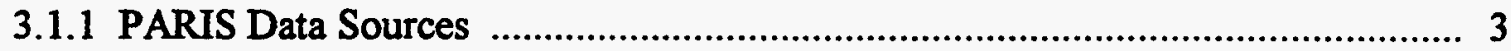

3.1.2 Table of Data Sources by Study .................................................................. 4

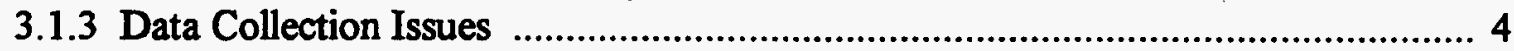

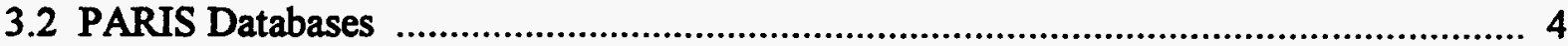

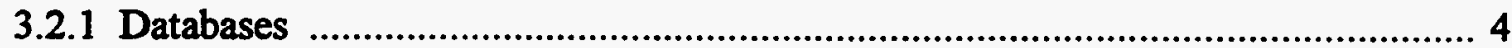

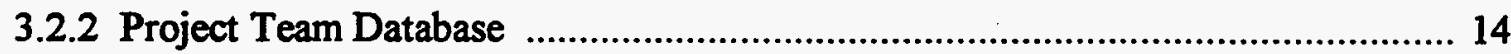

3.2.3 Distributed Database Processor ....................................................................... 14

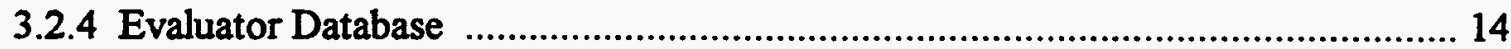

3.3 Data Management, Transfer, and Storage ............................................................. 14

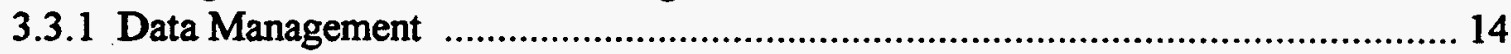

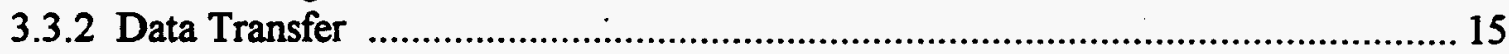

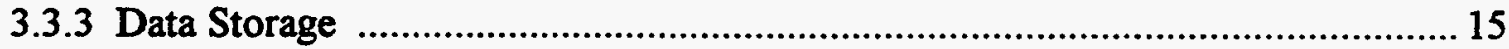

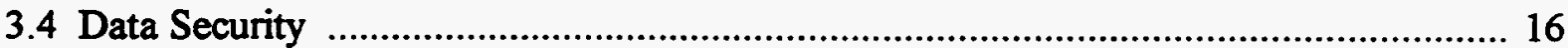

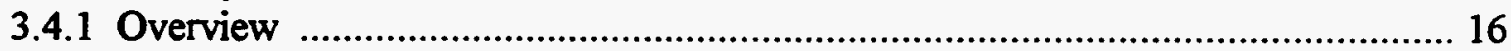

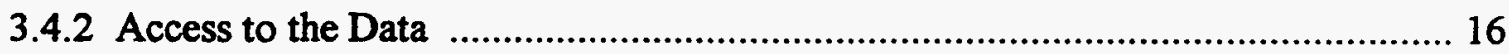

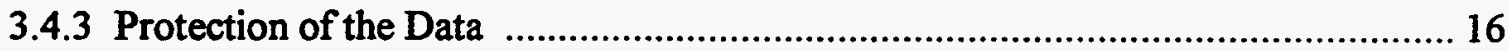

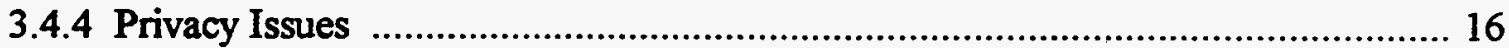

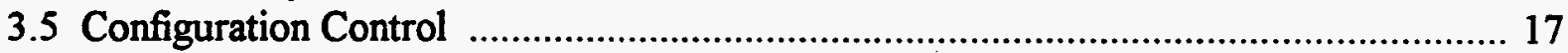

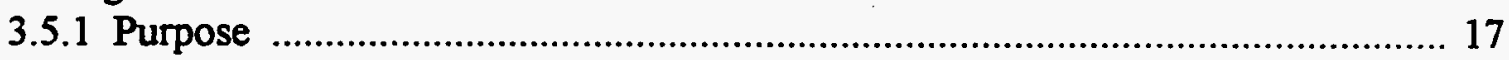

3.5.2 Control of Hardware and Software ........................................................... 17

3.5.3 Control of Data and Analysis Procedures ...................................................... 17

3.6 Document Test System, Traffic System, and Environment Condition History ................ 18

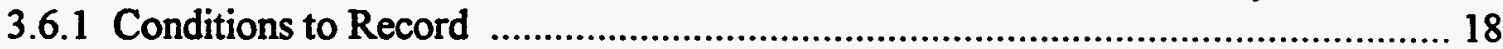

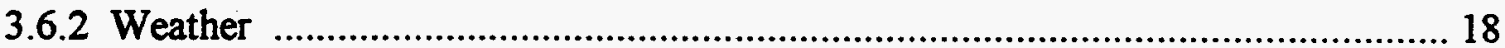

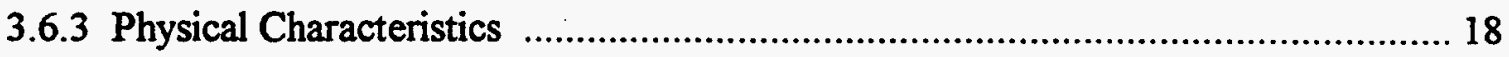




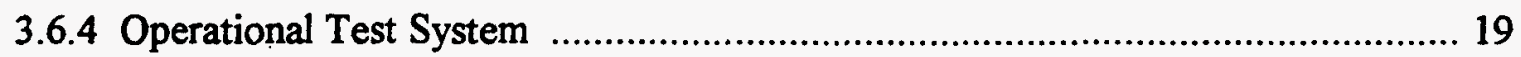

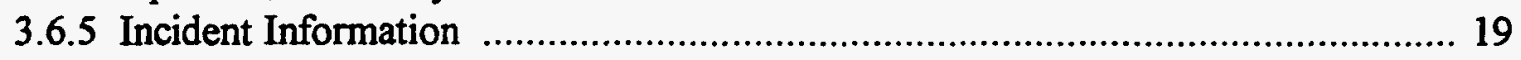

4. QUALITY CONTROL/QUALITY ASSURANCE PLAN ........................................... 19

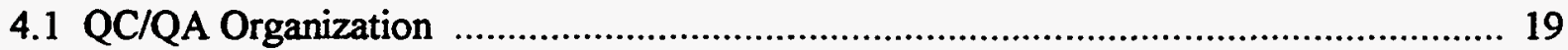

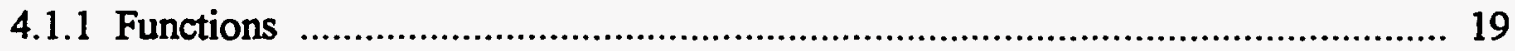

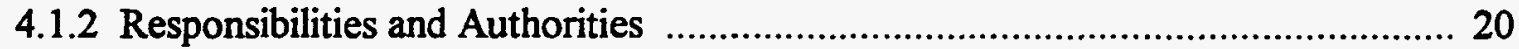

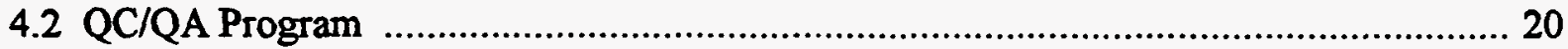

4.2.1 Policies and Objectives ……....................................................................... 20

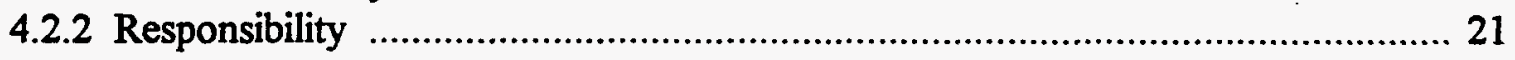

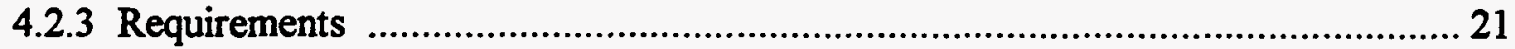

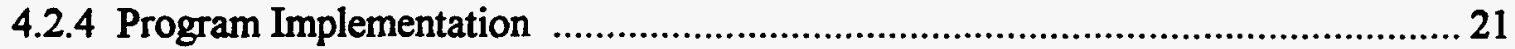

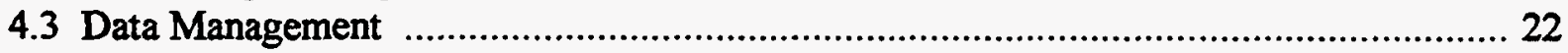

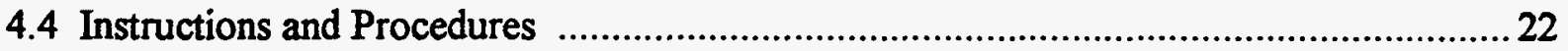

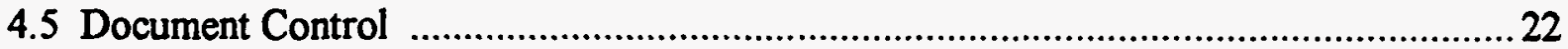

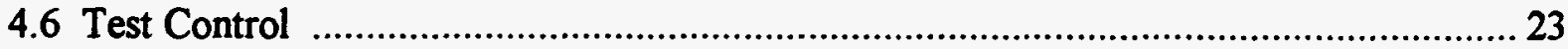

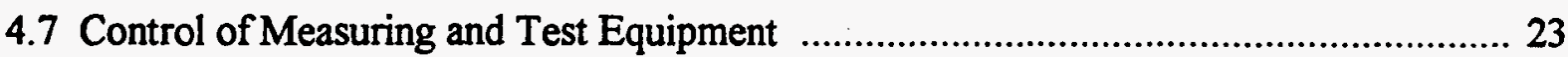

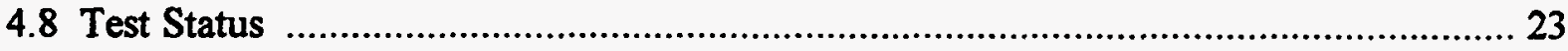

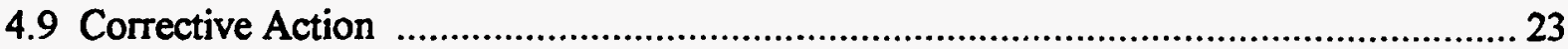

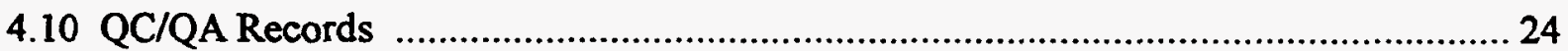

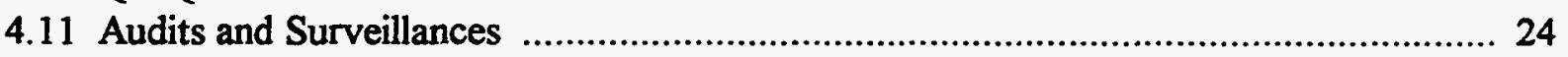

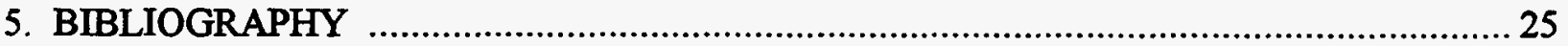

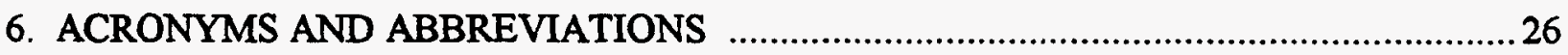

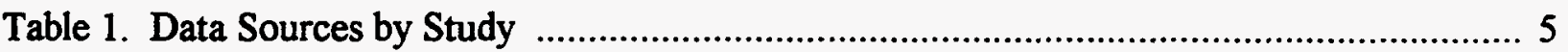

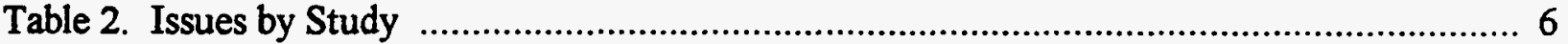




\begin{abstract}
A parking and routing information system (PARIS) is being designed and deployed at a test site on the Mountain Home Veterans Administration campus in Johnson City, Tennessee using three sensor technologies. The purpose of the PARIS project is to demonstrate innovative integration of vehicle sensing technologies with parking management strategies to improve mobility and relieve congestion associated with a growing medical/technology complex. Oak Ridge National Laboratory's (ORNL) role during phase I of the project is to act as the independent evaluator. This technical memorandum presents two plans, Data Management Plan and Quality Control/Quality Assurance ( $Q C / Q A)$ Plan, which were developed to support ORNL's responsibilities and functions. The purposes of the Data Management Plan are to coordinate the data needs which will be addressed in four individual evaluation test plans and to deal with the data issues facing the phase I evaluation as a whole. The objectives of the $Q C / Q A$ Plan are to ensure that the evaluation is conducted properly, to guarantee that the data which will be collected are valid and properly analyzed, and to make sure that the test results are accurately recorded and reported. The evaluation will be performed through the execution of four integrated studies (system performance, user acceptance, institutional and business issues, and transportation systems). The phase I evaluation data will be collected from 24 sources. Three databases will be established based upon these data (project team database, distributed database processor, and evaluator database). The Data Management Plan covers phase I data collection; data management, transfer, and storage; data security; configuration control; and documentation of the test system, traffic system, and environment condition history. During the evaluation phase, ORNL will be responsible for the management of the four studies and technical work necessary to implement the individual evaluation test plans. The QC/QA Plan describes the evaluation QC/QA program and organization. It also details: data management; QC/QA instruction and procedures; document and test control; control of measuring and test equipment; test status; corrective action; QC/QA records; and aüdits and surveillances.
\end{abstract}




\section{INTRODUCTION}

\subsection{Purpose of the Plans}

The Data Management Plan has two primary purposes. The first is to coordinate the data needs which will be addressed in the Johnson City, Tennessee (TN) intelligent transportation systems (ITS) parking and routing information system (PARIS) phase I individual evaluation test plans (Carter, 1997). The second purpose is to deal with the data issues facing the PARIS phase I evaluation as a whole.

The Quality Control/Quality Assurance $(Q C / Q A)$ Plan has three primary objectives. The first is to ensure that the four studies which will be performed during the Johnson City, TN ITS PARIS phase I evaluation are conducted properly. The second objective is to guarantee that the data which will be collected are valid and appropriately analyzed. The third is to make sure that the results from the evaluation studies are accurately recorded and reported. The $Q C / Q A P l a n$ is applicable to the four individual evaluation test plans.

\section{$1.2 \quad$ Background}

The purpose of the PARIS project is to demonstrate innovative integration of vehicle sensing technologies with parking management strategies to improve mobility and relieve congestion associated with a growing medical/technology (med/tech) complex. PARIS is being developed and implemented in a three-phased approach. Phase I, which is currently ongoing, is oriented toward the design and deployment of a PARIS at a test site on the Mountain Home Veterans Administration (VA) campus using three sensor technologies. In phase II, a parking garage will be constructed, integrating the sensors and PARIS developed in phase I. PARIS will also be extended to cover more parking facilities at the Mountain Home campus and adjacent areas during this phase. Phase III will continue to expand PARIS into the med/tech corridor, incorporate an intermodal transportation aspect, and construct a second intelligent parking facility (if full funding is secured).

\section{$1.3 \quad$ Scope}

The Data Management and $Q C / Q A$ Plans are based upon the guidelines provided in the Generic Intelligent Vehicle/Highway Systems (IVHS) Operational Test Evaluation Guidelines (MITRE, 1993). Consistent with these guidelines, six steps of the evaluation have been identified. These steps are:

1. Evaluation concept development;

2. Evaluation goal definition;

3. Evaluation definition;

4. Evaluation design (includes the Data Management and $Q C / Q A$ Plans, and the individual evaluation test plans); 
5. Data collection and analysis; and

6. Reporting.

The Phase I Work Plan (City of Johnson City, 1994) submitted and approved for this project, along with subsequent meetings and actions, satisfied the contents of steps 1 and 2 . The Evaluation Plan (Raytheon, 1996) fulfilled the requirements of step 3. The next action is for Oak Ridge National Laboratory (ORNL, the independent evaluator) to complete the individual evaluation test plans.

\section{PARIS EVALUATION STUDIES}

\subsection{PARIS Evaluation}

The evaluation of PARIS will be performed through the execution of four integrated studies. They include the:

1. System performance study;

2. User acceptance study;

3. Institutional and business issues study; and

4. Transportation systems study.

Each of these studies was covered in the Evaluation Plan and will be described in further detail in four independent evaluation test plans. They are briefly described below.

\subsection{System Performance Study}

The system performance study will evaluate the performance of PARIS and its subsystems. The study will assess: the PARIS architecture and performance as a whole; sensor performance, accuracy, and reliability under expected environmental conditions; processing architecture and performance characteristics; communications architecture and format; and variable message signs (VMS) performance and reliability.

\subsection{User Acceptance Study}

The user acceptance study will analyze the drivers' acceptance and perceptions of PARIS. It will assess: perception of PARIS usefulness; perception of reliability; aesthetic acceptance; and signing strategy and content.

\subsection{Institutional and Business Issues Study}

The institutional and business issues study will investigate PARIS project organization and management, regulatory and legal, human and facilities resources, financial, jurisdictional, and 
public/private issues. The study will assess: deployment issues; inter-agency cooperation; and historical considerations.

\subsection{Transportation Systems Study}

The transportation systems study will examine PARIS' alignment with ITS goals, guidelines, and documentation. It will assess: system safety; expandability/extendibility issues; compliance with national ITS objectives; and synchronization with the national system architecture.

\section{DATA MANAGEMENT PLAN}

\subsection{PARIS Data Collection}

\subsubsection{PARIS Data Sources}

Phase I evaluation data will be collected on PARIS from 24 sources. The sources are identified below. Any item marked with an asterisk $\left(^{*}\right)$ denotes a phase I program deliverable.

1. PARIS component documentation;

2. PARIS component specifications;

3. PARIS user manuals*;

4. System failure reports;

5. Maintenance reports;

6. System integration results*;

7. System requirements document*;

8. Final hardware description document*;

9. Time-lapsed VCR data;

10. Distributed database processor;

11. Parking implementation cost/benefit analysis*;

12. Commuter needs assessment*;

13. Commuter preference profile*;

14. Human factors study*;

15. Mountain Home VA engineering office;

16. VA regulations;

17. Johnson City med/tech corridor parking plans;

18. Intelligent Transportation Society of America (ITSA) documentation;

19. Federal Highway Administration (FHWA) guidelines;

20. National system architecture document;

21. Historical preservation laws;

22. Field measurements;

23. Questionnaires; and

24. Interviews. 
The first six sets of documents will be generated by Raytheon Company during phase I of the project. The system requirements and the final hardware description documents, and the timelapsed VCR data will also be produced by Raytheon. The distributed database processor will be one of PARIS' four distributed processors. Its functions will consist of storing sensor data and generating reports. The distributed database processor will also provide a graphical user interface with the real-time parking lot display, hardware status display, and VMS displays.

The parking implementation cost/benefit analysis will be generated by Wilbur Smith Associates. The commuter needs assessment will be performed and the preference profile will be derived by the Virginia Tech Center for Transportation Research. The human factors study in support of PARIS will be conducted by the University of Tennessee Transportation Center. The VA engineering office and VA regulations will be accessible at the Mountain Home VA center. The Johnson City med/tech corridor parking plans will be provided by the City of Johnson City.

ITSA documentation will be available from the Society's headquarters in Washington, D.C. FHWA guidelines and the national system architecture document will be obtainable from the United States Department of Transportation (DOT). Historical preservation laws will be accessible from either the Mountain Home VA or some other Federal government agency. Field measurements will be taken and questionnaires and interviews will be administered by the independent evaluator during the evaluation portion of the operational test.

\subsubsection{Table of Data Sources by Study}

Table 1 exhibits a cross tabulation that shows which PARIS studies will generate data for each source and which studies will use data from each source. At the intersection (cell) of a data source row with a study column, a $\mathrm{G}$ indicates that the respective study will generate data for the respective data source. Similarly, a U signifies that the study will utilize data from that source.

\subsubsection{Data Collection Issues}

The evaluation team, consisting of representatives from Raytheon, Wilbur Smith, and Virginia Tech, put together a list of issues associated with each of the four evaluation studies. The team also identified the data requirements and the formats of the data for each issue. This material was derived by the three team members working independently. The evaluation team subsequently met together to arrive at a consensus. Table 2, provided on pages $6-13$, presents the finalized issues, data, and formats for each study. The table subdivides each study into its corresponding objectives.

\subsection{PARIS Databases}

\subsubsection{Databases}

There will be three databases established as part of phase I of PARIS. They are as follows: 
Table 1. Data Sources by Study

\begin{tabular}{|c|c|c|c|c|}
\hline & \multicolumn{4}{|c|}{ Studies } \\
\hline & $\begin{array}{c}\text { Syatem Performance } \\
\text { Study }\end{array}$ & User Acceptance Study & $\begin{array}{l}\text { Institutional and } \\
\text { Business Iaves Study }\end{array}$ & $\begin{array}{l}\text { Transportation Systems } \\
\text { Study }\end{array}$ \\
\hline Dade Sonrees & & & & \\
\hline $\begin{array}{l}\text { PARIS Component } \\
\text { Documentation }\end{array}$ & $\mathbf{U}$ & & & \\
\hline $\begin{array}{l}\text { PARIS Component } \\
\text { Specifications }\end{array}$ & $\mathbf{U}$ & & & $\mathbf{U}$ \\
\hline PARIS User Manuals & & & & $\mathbf{U}$ \\
\hline System Failure Reports & $\mathrm{U}$ & & & \\
\hline Maintenance Reports & $\mathrm{U}$ & & & \\
\hline $\begin{array}{l}\text { System Integration } \\
\text { Resoults }\end{array}$ & $\mathrm{U}$ & & & \\
\hline $\begin{array}{l}\text { System Requirements } \\
\text { Document }\end{array}$ & $\mathrm{U}$ & & & \\
\hline $\begin{array}{l}\text { Final Hardware } \\
\text { Description Document }\end{array}$ & $\mathbf{U}$ & . & & \\
\hline Time-Lapsed VCR Data & $\mathbf{U}$ & & & \\
\hline $\begin{array}{l}\text { Distributed Database } \\
\text { Processor }\end{array}$ & $\mathbf{U}$ & & . & \\
\hline $\begin{array}{l}\text { Parking Implementation } \\
\text { Cost/Benefit Analysis }\end{array}$ & & & $\mathbf{U}$ & \\
\hline $\begin{array}{l}\text { Commuter Needs } \\
\text { Assessment }\end{array}$ & & $\mathbf{U}$ & & \\
\hline $\begin{array}{l}\text { Commuter Preference } \\
\text { Profile }\end{array}$ & & U & & \\
\hline Human Factors Study & & $\mathbf{U}$ & & $\mathbf{U}$ \\
\hline VA Engineering Office & & $\mathbf{U}$ & & \\
\hline VA Regulations & & & $\mathbf{U}$ & \\
\hline $\begin{array}{l}\text { Johnson City Med/Tech } \\
\text { Corridor Parking Plans }\end{array}$ & & & & $\mathbf{U}$ \\
\hline ITSA Documentation & & & & $\mathbf{U}$ \\
\hline FHWA Guidelines & & & & $\mathbf{U}$ \\
\hline $\begin{array}{l}\text { National System } \\
\text { Architecture Document }\end{array}$ & & & & $\mathbf{U}$ \\
\hline $\begin{array}{l}\text { Historical Preservation } \\
\text { Laws }\end{array}$ & & $\mathbf{U}$ & $U$ & \\
\hline Field Measurements & $\mathbf{G}$ & & & \\
\hline Questionnaires & & G & & \\
\hline Interviews & & $\mathbf{G}$ & $\mathbf{G}$ & G \\
\hline
\end{tabular}




\begin{tabular}{|c|c|c|}
\hline 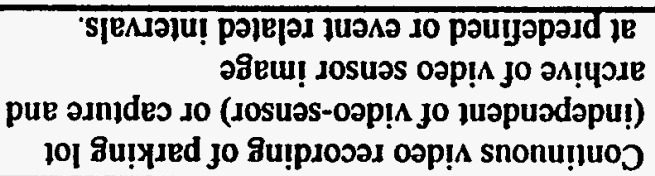 & Iu!pıosəy oәp! $\Lambda$ & 8u!yde d Jodosduw \\
\hline 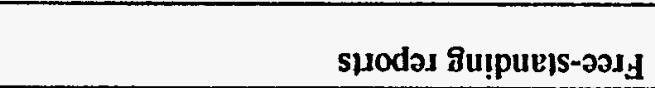 & 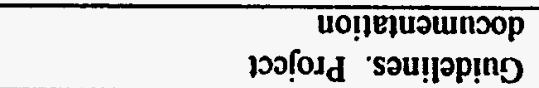 & 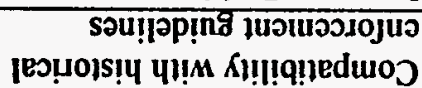 \\
\hline 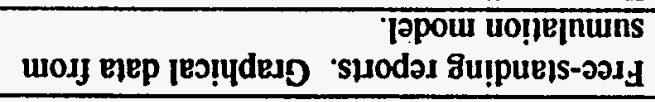 & 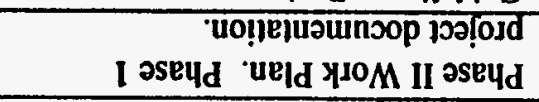 & 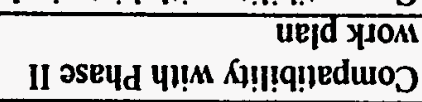 \\
\hline suodəx \&u!pue|s-əəə⿳亠口冋 & 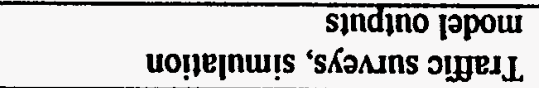 & 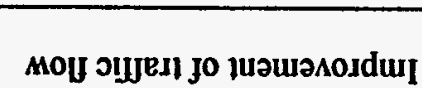 \\
\hline suodax gu!puejs-әәI & 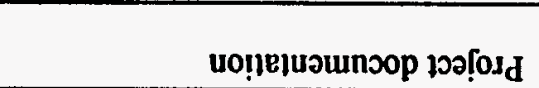 & 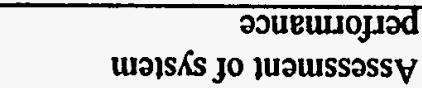 \\
\hline FEuLOS & EjEG & onss! \\
\hline & \multicolumn{2}{|c|}{ 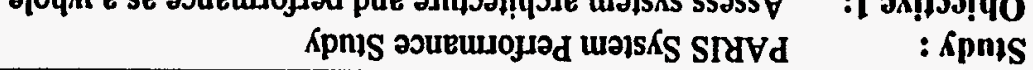 } \\
\hline
\end{tabular}




\begin{tabular}{|c|c|c|}
\hline $\begin{array}{lc}\text { Study : } & \text { PARIS System } \\
\text { Objective 2: } & \text { Assess sensor p }\end{array}$ & $\begin{array}{l}\text { rformance Study } \\
\text { ormance, accuracy and reliability }\end{array}$ & \\
\hline Issue & Data & Format \\
\hline \multirow[t]{2}{*}{ Assessment of sensor accuracy } & Actual Parking Status & $\begin{array}{l}\text { Verified status of each lot space. Status verified } \\
\text { either manually or automatically (if possible). }\end{array}$ \\
\hline & Correlation betwcen sensors & $\begin{array}{l}\text { Computer-generated report detailing sensor } \\
\text { output differences }\end{array}$ \\
\hline \multirow[t]{3}{*}{$\begin{array}{l}\text { Sensor performance at } \\
\text { environmental extremes }\end{array}$} & Temperature & Continuous reading, one reading per hour. \\
\hline & Humidity & Same as above. \\
\hline & Visibility & $\begin{array}{l}\text { Measured (if possible), otherwise subjective } \\
\text { assessment entered manually. Poor visibility may } \\
\text { be caused by fog, rain or snow. }\end{array}$ \\
\hline Inaccurate Baseline Condition & Actual Parking Status & $\begin{array}{l}\text { Verified status of each lot space at a given point } \\
\text { in time, e.g., time of low activity (night) or at } \\
\text { time of recovery from power failure, } \\
\text { maintenance activity etc. }\end{array}$ \\
\hline Power Supply & Voltage, Frequency & $\begin{array}{l}\text { Continuous or periodic measurements of power } \\
\text { supply parameters considered critical to } \\
\text { technologies being used. }\end{array}$ \\
\hline Electrical Interference & $\log$ & $\begin{array}{l}\text { Manually entered record of lightning or other } \\
\text { events which may be a source of electrical } \\
\text { interference }\end{array}$ \\
\hline MTBF & Log & $\begin{array}{l}\text { Record of maintenance and repair activities for } \\
\text { all sensors }\end{array}$ \\
\hline Physical Damage & Log & $\begin{array}{l}\text { Manually entered record of evidence of physical } \\
\text { damage or tempering with field equipment. All } \\
\text { field equipment should be inspected periodically } \\
\text { (once per day or weekly). }\end{array}$ \\
\hline Equipment Reliability & Log & $\begin{array}{l}\text { Automatic logging of system diagnosed } \\
\text { equipment failures, plus manually entered failure } \\
\text { records for events not automatically detected and } \\
\text { logged. }\end{array}$ \\
\hline
\end{tabular}




\begin{tabular}{|c|c|c|}
\hline \multicolumn{3}{|c|}{$\begin{array}{ll}\text { Study : } & \text { PARIS System Performance Study } \\
\text { Objective 3: } & \text { Assess the lot and central processing architecture and performance characteristics }\end{array}$} \\
\hline Issue & Data & Format \\
\hline Processing Capacity & $\begin{array}{l}\text { Frequency of change of stalus. Networking } \\
\text { architecture description. }\end{array}$ & $\begin{array}{l}\text { Maximum number of changes in individual space } \\
\text { status in a given interval of time. Value could be } \\
\text { either as measured by system or projected from } \\
\text { parking surveys. }\end{array}$ \\
\hline $\begin{array}{l}\text { System Response Time to } \\
\text { Operator Requests }\end{array}$ & $\begin{array}{l}\text { Measurement of time taken for system to perform } \\
\text { specific functions }\end{array}$ & $\begin{array}{l}\text { Manually timed or system timed duration to show } \\
\text { display, implement new message to VMS or print } \\
\text { report-under normal, peak-hour load conditions. }\end{array}$ \\
\hline \multirow{2}{*}{$\begin{array}{l}\text { System Performance Following } \\
\text { Major Equipment Failures (Lot } \\
\text { or Central Processors) }\end{array}$} & $\begin{array}{l}\text { Response Time for overall system while } \\
\text { recovering form Lot Processor failure. }\end{array}$ & $\begin{array}{l}\text { See System Response Time to Operator Requests, } \\
\text { above. }\end{array}$ \\
\hline & System Accuracy & See Objective 2: Inaccurate Baseline Condition \\
\hline $\begin{array}{l}\text { System delay time from actual } \\
\text { parking to UMS update }\end{array}$ & $\begin{array}{l}\text { Measurement from sensor recognition to central } \\
\text { processor monitor update to VMS update. }\end{array}$ & Manual measurements. \\
\hline
\end{tabular}




\begin{tabular}{|c|c|c|}
\hline \multicolumn{3}{|c|}{$\begin{array}{ll}\text { Study : } & \text { PARIS System Performance Study } \\
\text { Objective 4: } & \text { Assess the communications architecture }\end{array}$} \\
\hline Issue & Data & Format \\
\hline \multirow[t]{2}{*}{ Communication Reliability } & Hardware failures & $\begin{array}{l}\text { System generated record of intermittent and } \\
\text { steady communication failures, plus manually } \\
\text { entered records as necessary. }\end{array}$ \\
\hline & Detected Error Rates & $\begin{array}{l}\text { Record frequency with which system } \\
\text { automatically requests the resending to a message } \\
\text { due to detected checksum error or other } \\
\text { automatic check on communications validity. } \\
\text { Frequency to be recorded in intervals consistent } \\
\text { with other data records to facilitate cross } \\
\text { checking - for example, do we get more errors } \\
\text { when weather conditions are extreme or power } \\
\text { supply fluctuates? }\end{array}$ \\
\hline Power loss & Log & $\begin{array}{l}\text { Processor data-base log showing status of power } \\
\text { supplied to each communications box }\end{array}$ \\
\hline Range & Project Plans & $\begin{array}{l}\text { Record length of each communication channel, } \\
\text { and key characteristics, e.g., for others record } \\
\text { medium (fiber, coaxial, twisted pairs), } \\
\text { communication protocols etc. }\end{array}$ \\
\hline Communication Capacity & Volume of Data & $\begin{array}{l}\text { Record volume of data transmitted through key } \\
\text { communication channels under normal peak- } \\
\text { hour conditions. This can be compared to } \\
\text { theorelical capacity of the channel. }\end{array}$ \\
\hline $\begin{array}{l}\text { System response time to } \\
\text { external events }\end{array}$ & Time Measurement & $\begin{array}{l}\text { Manually entered or automatically calculated } \\
\text { duration between detection of an event and } \\
\text { completion of system response. For example, } \\
\text { when a lot processor detects a car parking which } \\
\text { processor detects a car parking which puts the lot } \\
\text { over the threshold of being full, then the time t } \\
\text { display an appropriate VMS message should be } \\
\text { recorded. This time may be influenced less by } \\
\text { data transmission speed or processing power than } \\
\text { by system architecture, such as the rate of polling } \\
\text { lot processors (once a second, once a minute } \\
\text { etc.). }\end{array}$ \\
\hline
\end{tabular}




\begin{tabular}{|l|l|l|}
\hline $\begin{array}{l}\text { Study : } \\
\text { Ohjective 4: } \quad \text { Assess the communications architecture }\end{array}$ \\
\hline Remote access failure & Log & $\begin{array}{l}\text { Data base log of all remote access activity which } \\
\text { would show any failed attempts to access the } \\
\text { system from a remote location }\end{array}$ \\
\hline Component failure & Log & Records of all maintenance and repair activities \\
\hline
\end{tabular}




\begin{tabular}{|c|c|c|c|}
\hline \multicolumn{4}{|c|}{ PARIS System Performance Study } \\
\hline & Issue & Data & Format \\
\hline & Placement of VMS & User survey. & $\begin{array}{l}\text { Survey result should address issues of sign } \\
\text { visibility and effectiveness. }\end{array}$ \\
\hline \multirow{3}{*}{ ஐ } & \multirow[t]{2}{*}{ Accuracy of VMS information } & $\begin{array}{l}\text { User survey responses indicate lot not full, when } \\
\text { VMS says it is. }\end{array}$ & $\begin{array}{l}\text { User surveys. Format of survey results } \\
\text { (particularly time, date) should be consistent with } \\
\text { other data items to facilitate cross-checking. } \\
\text { Possible causes: inaccurate detection of parking } \\
\text { status, inaccurate baseline conditions, time gap } \\
\text { between reading VMS and observing lot. Could } \\
\text { also be survey/Observer error - empty spaces may } \\
\text { be reserved for special class of user (volunteers), } \\
\text { unknown to observer. }\end{array}$ \\
\hline & & $\begin{array}{l}\text { User survey responses indicate lot is full, when } \\
\text { VMS says it has spaces. }\end{array}$ & $\begin{array}{l}\text { User surveys. Format as above. Possible causes: } \\
\text { inaccurate detection of parking status, inaccurate } \\
\text { base line conditions, time gap between reading } \\
\text { VMS and observing lot. Could also be } \\
\text { survey/observer error - spaces may not have been } \\
\text { visible to the observer - did he/she drive down } \\
\text { every aisle? }\end{array}$ \\
\hline & VMS message ignored & User survey responses. & $\begin{array}{l}\text { User surveys. Survey design and database format } \\
\text { should identify reason message ignored; too long, } \\
\text { didn't understand, didn't know it referred to me } \\
\text { looking at other signs, traffic etc. Format should } \\
\text { allow cross checking with other respondent } \\
\text { characteristics, type of parker (employee, } \\
\text { patient), campus entrance used etc., weather } \\
\text { conditions (bright sun, rain). }\end{array}$ \\
\hline
\end{tabular}




\begin{tabular}{|c|c|c|}
\hline \multicolumn{3}{|c|}{$\begin{aligned} & \text { Study : } \text { PARIS User Acceptance Study } \\
& \text { Ohjective 1. } \text { Assess perceptions of system usefulness } \\
& \text { 2. } \text { Assess perception of reliability } \\
& \text { 3. } \text { Assess aesthetic acceptance } \\
&\end{aligned}$} \\
\hline Issue & Data & Format \\
\hline $\begin{array}{l}\text { Perception of usefulness and } \\
\text { effectiveness. }\end{array}$ & User surveys & $\begin{array}{l}\text { Format to facilitate identification of reasons for } \\
\text { perception and potential underlying causes, e.g., } \\
\text { inaccurate detection of parking status, too } \\
\text { confusing etc. }\end{array}$ \\
\hline Perception of reliability & User surveys & As above. \\
\hline Perception of aesthetics & User surveys & $\begin{array}{l}\text { Format to facilitate identification of reasons for } \\
\text { perception - for example, VMS signs too big } \\
\text { and/or ugly, too many sign (of all types), too may } \\
\text { metal equipment enclosures visible around the } \\
\text { campus. }\end{array}$ \\
\hline $\begin{array}{l}\text { VMS not intelligible or } \\
\text { understood by motorists }\end{array}$ & User surveys and observations & $\begin{array}{l}\text { Survey results to determine if motorists see and } \\
\text { understand sign instructions. }\end{array}$ \\
\hline $\begin{array}{l}\text { Motorist non-compliance to } \\
\text { system instructions }\end{array}$ & Observations, video records and user survey & $\begin{array}{l}\text { Historical data on traffic flow and traffic } \\
\text { problems. }\end{array}$ \\
\hline
\end{tabular}




\begin{tabular}{|c|c|c|}
\hline \multicolumn{3}{|c|}{$\begin{aligned} & \text { Study : } \text { PARIS Institutional Issues Study } \\
& \text { Objective 1. } \text { Assess deployment issues } \\
& \text { 2. } \text { Assess inter-agency cooperation } \\
& \text { 3. } \text { Assess system safety } \\
&\end{aligned}$} \\
\hline Issue & Data & Format \\
\hline \multirow[t]{3}{*}{$\begin{array}{l}\text { Assessment of deployment } \\
\text { issues }\end{array}$} & Project documentation & $\begin{array}{l}\text { Free-standing documents, probably not part of a } \\
\text { computerized database. Documents would } \\
\text { include interview summaries, cost data, Parking } \\
\text { Implementation Cost/Benefit Analysis report and } \\
\text { Human Factor Study report. }\end{array}$ \\
\hline & Cost/benefit analysis & \\
\hline & Environmental / aesthetic impact study results & \\
\hline \multirow[t]{2}{*}{ Interagency cooperation } & Interview results & \\
\hline & Project documentation & \\
\hline Assessment of system safety & Safety statistics & $\begin{array}{l}\text { Safety record before and after implementation of } \\
\text { the PARIS project. }\end{array}$ \\
\hline
\end{tabular}

\begin{tabular}{|c|c|c|}
\hline \multicolumn{3}{|c|}{$\begin{aligned} & \text { Study : } \text { PARIS Transportation System Study } \\
& \text { Objective 1. } \text { Compliance with National ITS objectives } \\
& \text { 2. } \text { Assess synchronization with national system architecture } \\
&\end{aligned}$} \\
\hline Issue & Data & Format \\
\hline $\begin{array}{l}\text { Assessment of compliance with } \\
\text { ITS objectives }\end{array}$ & Published FHWA reports, guidelines. & $\begin{array}{l}\text { Free-standing documents probably not part of a } \\
\text { computerized database. }\end{array}$ \\
\hline \multirow[t]{3}{*}{ System effectiveness } & System safety statistics & Historical data and observations \\
\hline & Traffic level and turning movements within lot & Video recordings \\
\hline & Motorists waiting time & Video recordings and observations \\
\hline System expandability & Project documentation & \\
\hline $\begin{array}{l}\text { Ability of system to interface to } \\
\text { surrounding infrastructure }\end{array}$ & Infrastructure plans and projections & Evaluation reports \\
\hline
\end{tabular}


1. Documentation produced by the project team;

2. Data stored in the distributed database processor; and

3. Data collected by the evaluator.

\subsubsection{Project Team Database}

Material generated by the project team (i.e., PARIS component documentation and specifications, PARIS user manuals, system failure and maintenance reports, system integration results, system requirements and final hardware description documents, time-lapsed VCR data, parking implementation cost/benefit analysis, commuter needs assessment and preference profile, and human factors study) will be the contents of the project team database. Raytheon will be the repository for these items.

\subsubsection{Distributed Database Processor}

The data contained in the distributed database processor's database will consist of information from the four types of lot processors. These lot processors will transfer infrared space sensor, fiber optic space sensor, video image processing, and fiber optic vehicle counter data. The distributed database processor will be located in the PARIS control center and be an International Business Machines compatible personal computer running the Microsoft Windows 95 operating system. This computer will have two 1.6 gigabyte EIDE drives for storage of material.

\subsubsection{Evaluator Database}

Information gathered by the independent evaluator (i.e., field measurements and questionnaire and interview data) will be the substance of the evaluator database. Some selected information will however not be part of the database. Documentation that will not be archived in this database include: personal data that would violate the confidentiality of the users; material discussed and/or provided by the project team members for the institutional and business issues study; and proprietary information.

\subsection{Data Management, Transfer, and Storage}

\subsubsection{Data Management}

PARIS will support both data collection and data management activities. It will be the responsibility of the evaluation team to ensure that data collection and management capabilities are suitably in place. The distributed database processor is being designed so that it will have the capability to turn evaluation data collection and storage both on and off.

Raytheon will be accountable for managing and maintaining the project team database. They will also be responsible for overseeing and handling the distributed database processor database. 
ORNL will be responsible for cataloging, managing, and maintaining the evaluator database until phase I of PARIS is complete.

\subsubsection{Data Transfer}

Each project team member will be responsible for submitting the material that it produces as part of the PARIS project to Raytheon for incorporation within the project team database. One of Raytheon's roles in the PARIS project will be to ensure that the items in the database are available to other project team members, the independent evaluator, the City of Johnson City, TNDOT, and FHWA upon request.

The Mountain Home VA will make personnel in their engineering office accessible for consultation with the independent evaluator. They will also provide regulations if requested to do so. The City of Johnson City will furnish the med/tech corridor parking plans for use by ORNL. It is assumed that ITSA and FHWA will supply documentation and guidelines. It is also conjectured that some Federal government agency will provide the historical preservation laws.

The distributed database processor database will be available to the independent evaluator via the remote processor in the PARIS control center. Data will be transferred electronically via both a bulletin board and modems. The external interface will be provided by World Group Bulletin Board Service software. There will be a variety of pre-formatted reports available. These reports will be based upon the historical data contained in the distributed database processor database. The user will specify the interval of time which the report will cover. Parking lot and VMS status will be available in textual formats based upon the latest data that are stored in the database.

ORNL will transfer the evaluator database to Raytheon at the end of phase I. At their discretion, Raytheon will subsequently submit the database to the City of Johnson City, TNDOT, and/or FHWA.

\subsubsection{Data Storage}

Raytheon will be responsible for storing the information in the project team database and the data in the distributed database processor database. The independent evaluator will be accountable for the storage of the material in the evaluator database. If requested to do so, Raytheon will furnish data from the three databases to the national ITS data repository.

Formats and locations of the three databases will be coordinated among the evaluation team members and ORNL. Database structure will be important because it will affect the efficiency of storing the data generated during the test and data analysis. Data storage design decisions which will be addressed include:

1. Data storage form and duration;

2. Storage media; 
3. Storage location;

4. Data storage during the conduct of the individual evaluation test plans;

5. Data transmission method; and

6. Authorization for and implementation of data access procedures.

\subsection{Data Security}

\subsubsection{Overview}

Data security is important because the main product from an operational test is the collected data. Significant items to be considered in regards to data security include:

1. Access to the data;

2. Protecting the data from destruction and/or corruption; and

3. Privacy issues associated with access and use.

\subsubsection{Access to the Data}

Remote electronic access to the distributed database processor database will be provided such that only authorized operators may access or display information. The following two security levels will be provided:

1. View status - Observe the PARIS status; and

2. System interaction - Read database records.

The evaluator database will only be accessible to constituents of the independent evaluator's team until the phase I operational test is complete. During the evaluation phase neither Raytheon nor any other project team member will be able to review or analyze the information in this database.

\subsubsection{Protection of the Data}

All data collected on the two hard-drives of the distributed database processor will periodically be backed-up onto a removable drive. This procedure will protect the electronic data from potentially being corrupted. The material in the project team and evaluator databases will be reproduced. These working copies will be used for the actual data analysis. The originals/masters will be annotated, catalogued, and then stored in safe places at Raytheon and ORNL, respectively. A log of all data items will be kept with the master copies. Additional working copies will be made from the originals if the working copy in use is accidently or maliciously destroyed, or otherwise deemed unusable.

\subsubsection{Privacy Issues}

The questionnaire and interview data in the evaluator database will be used only for the purpose 
of evaluating PARIS and other similar systems. Data will be copied and made available for analysis purposes only. Results using this evaluator database material will be published only in aggregate form, without naming any participants. In the event that any singular reference is deemed a critical component of the information to be presented, ORNL will seek the consent of the individual from whom the data originated. The material will be published only if this consent has been granted. No personal information about participants will be released outside the PARIS evaluation process unless the independent evaluator is required to do so by a valid court order.

\subsection{Configuration Control}

\subsubsection{Purpose}

Configuration control provides the means for identifying and retrieving evaluation data, and identifying the state of the operational test system when the data were collected. Configuration control ensures that the data can be accessed when needed for analysis, and that changes in the system configuration (which potentially could affect the performance) are accounted for in the analysis. The hardware, software, and data analysis procedures must be under configuration control.

\subsubsection{Control of Hardware and Software}

Raytheon will be responsible for configuration control of the hardware and software of PARIS. It will be necessary for them to advise the independent evaluator when any configuration change is anticipated or has taken place. As ORNL is advised of configuration changes, the configuration tables prepared at the beginning of the evaluation data collection phase of the test will be updated. The independent evaluator will then analyze the change to determine its effect on the data already collected and whether old data can be mixed with new data.

\subsubsection{Control of Data and Analysis Procedures}

Configuration control of the project team database and the distributed database processor database will rest with Raytheon. ORNL will be accountable for configuration control of the evaluator database. The information in this database will be cross indexed by test identification and by date and time. Configuration control of the data analysis procedures will also be the responsibility of the independent evaluator.

ORNL will maintain a logbook for the duration of the test period. The logbook will include recordings of events and observations to be used to interpret and understand the flow of the test, major weather and event occurrences, and other items useful in interpreting the data. It will contain, as a minimum, the items below.

1. Entries concerning the configuration and configuration changes of PARIS;

2. Notes regarding procedures utilized and changes made to existing plans; 
3. Comments received from operators in regards to the operation of the hardware and/or unusual conditions encountered;

4. Information needed to enhance the use or understanding of the collected data;

5. Dates and times of data collection;

6. Dates, times, and descriptions of events that might impact on use of the data for analysis purposes;

7. Observations that might have impact on any aspect of the test or analysis, especially extendibility or improvement;

8. Directions received or provided;

9. Data locations and filenames; and

10. Any other pertinent information for the evaluation.

The logbook will be used by the independent evaluator and provide a record on the status of the evaluation. Records will be at a level of detail sufficient for an assistant or follow-on evaluator to understand what has occurred and why.

\subsection{Document Test System, Traffic System, and Environment Condition History}

\subsubsection{Conditions to Record}

Influences outside the control of the independent evaluator, commonly called extraneous variables, will affect the data collected. Although there is no control, documenting the conditions during the evaluation will allow for the interpretation of the data in light of the conditions. Conditions to be recorded include:

1. Weather;

2. Physical characteristics of the parking lots on the Mountain Home VA campus;

3. State of the operational test system; and

4. Incidents.

\subsubsection{Weather}

Pertinent weather conditions will be logged via the National Weather Service (NWS) at Tri-City Airport in Bristol, TN. Manual log entries of temperature and humidity data on the Mountain Home campus will supplement the NWS data. The temperature and humidity will be recorded via a weather sensor located outside the control center in building 37 at the VA center.

\subsubsection{Physical Characteristics}

Changes over time of the physical characteristics of parking lots $\mathrm{C}, \mathrm{D}$, and $\mathrm{E}$ at the VA will be recorded during the evaluation portion of phase I. Items such as parking lot closure or blockage, parking lot aisle closure or obstruction, and particular parking space closure or blockage will be gathered. Also, any parking lot construction and/or repairs will be recorded. The data will be 
collected by the Mountain Home VA engineering office and via video imaging cameras in parking lots $\mathrm{C}, \mathrm{D}$, and $\mathrm{E}$.

\subsubsection{Operational Test System}

The state of PARIS (i.e., sensors, lot processors, distributed processors, communication subsystem, and VMS) may evolve as the operational test proceeds. As a result any changes which occur over the course of the phase I evaluation will be recorded by Raytheon. The state of the test system will be defined by records of hardware configurations and dates in use, software versions and dates in use, and database versions and dates in use.

\subsubsection{Incident Information}

Other incidents which might affect the operational test and/or environment, besides weather and changes in the physical characteristics of the parking lots and PARIS over time, will be recorded by the independent evaluator, Raytheon, and/or the VA engineering office. Traffic accidents on the Mountain Home campus will be logged by the VA police department. Incident information to be recorded include: identification (for storage and retrieval), time of occurrence and duration, type of incident, and special events.

\section{QUALITY CONTROL/QUALITY ASSURANCE PLAN}

\subsection{QC/QA Organization}

The independent evaluator will be responsible for the management of the PARIS phase I evaluation and the four studies, and for the technical work necessary to implement the individual evaluation test plans. The execution of these responsibilities will reside with the ORNL principal investigator.

\subsubsection{Functions}

The functions that the independent evaluator will perform to achieve the stated objectives of the $Q C / Q A$ Plan and to fulfill its ultimate responsibilities for the PARIS evaluation are as follows:

1. Development of a plan for the conduct of the evaluation QC/QA program;

2. Assignment of evaluation $Q C / Q A$ program execution responsibilities to appropriate evaluation participants;

3. Development of working plans and procedures for the conduct of evaluation QC/QA program activities;

4. Appropriate staffing and organization to implement the evaluation QC/QA program activities; and

5. Implementation of evaluation $\mathrm{QC} / \mathrm{QA}$ program activities. 


\subsubsection{Responsibilities and Authorities}

The ORNL principal investigator will coordinate the evaluation efforts with Raytheon (the PARIS program manager). The principal investigator will be responsible for PARIS evaluation integration and management, evaluation planning, project administration, customer liaison, and direction of all evaluation development and study design, procurement, the four studies, data collection and analysis, reporting, and the evaluation QC/QA program.

A PARIS evaluation QC/QA program manager will be assigned to the project. He/she will report to the ORNL principal investigator. The independent evaluator's principal investigator will delegate the responsibility for establishing, maintaining, directing, and managing an effective QC/QA program for the PARIS evaluation to the QC/QA program manager. In carrying out these responsibilities the program manager will be authorized to:

1. Establish and implement a program of review and concurrence with evaluation qualityaffecting documents and activities for inclusion of appropriate quality program elements;

2. Establish and implement a monitoring program of audits and surveillances over the PARIS evaluation to verify that work is being performed in accordance with the established quality program requirements;

3. Establish and implement a program for tracking corrective actions to identified problems and verifying their effective implementation; and

4. Notify the independent evaluator's principal investigator of unsatisfactory data collection, analysis and/or reporting, or unapproved practices and, if necessary, stop the related effort.

\subsection{QC/QA Program}

The provisions of the PARIS evaluation QC/QA program are described below and presented to demonstrate how the evaluation will meet a number of criteria.

\subsubsection{Policies and Objectives}

The policies and objectives of the PARIS evaluation QC/QA program will be to:

1. Assure the attainment of the level of quality necessary for the assessment of the PARIS evaluation goals and objectives;

2. Assure that systems and components installed for PARIS during phase I conform to specified requirements;

3. Assure that the four evaluation studies are conducted properly, the data collected are valid and appropriately analyzed, and the results from the studies are accurately recorded and reported; and 
4. Assure that appropriate $\mathrm{QC} / \mathrm{QA}$ activities are implemented by the independent evaluator.

\subsubsection{Responsibility}

The ORNL principal investigator will be responsible for and have management overview involvement in the PARIS evaluation QC/QA program. Execution of the QC/QA program will rest with the PARIS evaluation functional elements as detailed in the implementing procedures. Development of the PARIS QC/QA program and its management will be performed primarily by the independent evaluator's QC/QA staff, while other elements of the independent evaluator will be primarily responsible for performing selected technical functions for the proper execution of the evaluation $Q C / Q A$ program.

\subsubsection{Requirements}

The independent evaluator will establish and implement a PARIS evaluation QC/QA program in accordance with the quality requirements of Lockheed Martin Energy Systems, Incorporated Quality Program Description Y/QD-15, Revision 2 (1995). This document closely parallels ASME NQA-1 ( $Q A$ Requirements for Nuclear Facilities, 1989), ASME NQA-2 ( $Q A$ Requirements for Nuclear Facility Applications, 1990), and International Standards Organization standards 9001 and 9002.

\subsubsection{Program Implementation}

The PARIS evaluation QC/QA program is described in this $Q C / Q A$ Plan. The plan will be maintained as a controlled document with a document number and revision numbers, and modified as necessary to keep current with the PARIS evaluation practices.

Implementation of the PARIS evaluation QC/QA program will be accomplished through the detailed procedures contained in the independent evaluation test plans. The implementing procedures will be written in such a manner as to identify the activities that will be performed and to provide activity control to an extent consistent with their importance.

The independent evaluator will provide ORNL support personnel training on the evaluation QC/QA program provisions and implementing procedures. Contractors or consultants, if any, supporting the evaluation will be treated as project staff and work under the established PARIS evaluation QC/QA program provisions. A progress report addressing the evaluation QC/QA program will be prepared and submitted monthly to the ORNL principal investigator. This report will provide one means of bringing quality problems to the attention of the independent evaluator's management. 


\subsection{Data Management}

During the evaluation phase, the independent evaluator will review the time-lapsed VCR data and distributed database processor database approximately every two working days. The investigation will primarily consist of a "spot check" of a few randomly selected samples to ensure that accurate data are being recorded by PARIS. A portion of the data will be processed to verify the data processing procedures and to identify any trends in the data that would suggest areas needing more attention or a revision in procedure. No detailed analysis will, however, be performed on the data at this time. Any system problems which are identified will be reported to Raytheon.

The field measurements which will be taken and the questionnaires and interviews which will be conducted by the independent evaluator will be examined within three days of the gathering or administration. The material will be critiqued for completeness and quality of the information, and integrity and rationality of the data. The data will also be searched for their adequacy for later analysis. Again, no detailed analysis will be performed at this time. As the need arises, feedback will be provided to the data recorders to ensure the data's usefulness.

QC/QA of the data processing and analysis, and subsequent interpretation will be provided by close supervision and review of the work of research assistants by senior investigators, who will apply both reasonableness checks and statistical verifications to the data.

\subsection{Instructions and Procedures}

The PARIS evaluation QC/QA program will require that all activities affecting quality be accomplished with documented instructions and procedures. The independent evaluator will use written process procedures to implement the evaluation QC/QA program to provide assurance that all activities affecting quality are planned, controlled, and documented as appropriate. When issued, the procedures will be mandatory for personnel either performing or verifying qualityrelated activities for the PARIS evaluation. The technical information related to the evaluation is and will be contained in the Evaluation Plan, the Data Management Plan, and the independent evaluation test plans.

\subsection{Document Control}

Documents for the PARIS evaluation will be controlled. The implementing document control measures will be contained in various procedures within the evaluation QC/QA program. Documents subject to control include, but are not limited to: the Evaluation Plan, the Data Management Plan, the independent evaluation test plans, and evaluation reports. Controls will be imposed for initial review and approval actions, release of the documents, and distribution to designated personnel who either perform or verify quality-related work. Revisions to these documents will be reviewed and approved by organizations that approved the original document before release and distribution. 


\subsection{Test Control}

The four evaluation studies will be governed by the written and approved independent evaluation test plans. It will be the responsibility of the personnel initiating the studies to assure that the test plans have been prepared and approved by appropriate personnel. Data will be collected and analyzed, and testing results will be recorded in accordance with the independent evaluation test plans. They will periodically be reviewed to assure: acceptability of the study, validity of the data, appropriateness of the data analysis, and accuracy of the results. The data and the results will be maintained by the appropriate independent evaluator's management office.

The personnel responsible for conducting the testing will identify test equipment that requires calibration and assure that the equipment is calibrated before use. Hold points will be established to provide verification of test performance, as appropriate.

\subsection{Control of Measuring and Test Equipment}

Measuring and test equipment used to obtain the studies data will be controlled through a program of periodic calibration. The responsibility for this program will reside with the independent evaluator. All instruments requiring calibration will be labeled to identify their calibration status. The label will include the identification number, by whom it was calibrated, the date of the last calibration, and when the next calibration is due. When labeling is impractical, the instruments will be identified and documentation equivalent to the label will be maintained by the user.

When instruments are found to be out of tolerance, the appropriate evaluation study leader will be notified. He will determine the effect of the instrument error on any study data taken since the last calibration and make sure that the equipment malfunction is repaired. The program for control and calibration of instruments will be monitored by the independent evaluator's QC/QA staff to verify program acceptability and implementation.

\section{$4.8 \quad$ Test Status}

Activities performed by the independent evaluator will be controlled through the use of work plans and the independent evaluation test plans. These plans will include provisions related to providing the status of activities as they are being accomplished and documenting the results of the studies. In addition, various test event logs will be maintained during the PARIS evaluation. If at any time during the evaluation, a nonconforming item or a failure is discovered it will be documented within 24 hours and dispositioned.

\subsection{Corrective Action}

When conditions averse to quality are detected, they will be documented by means of nonconformance, occurrence, or audit/surveillance reports. All of these reports will require a plan 
for corrective action to prevent recurrence. Depending upon the nature and frequency of the nonconformances and deficiencies, follow-up action will be performed to verify implementation of the corrective action by surveillance.

\subsection{QC/QA Records}

PARIS evaluation QC/QA records are items and/or documents that furnish evidence of the quality of the evaluation. The independent evaluator will establish a system of control that will provide for the identification, authentication, preservation, and retrieval of QC/QA records. The duration of record storage will be determined on an individual basis and appropriately designated on the record. The independent evaluator will maintain an index of all QC/QA records in the records system. QC/QA records will be stored in a facility that provides for protection from damage, deterioration, or loss. Access to these records will be controlled and removal of record originals will not be permitted.

The evaluation study leaders will be responsible for designating which items or documents pertaining to their cognizant areas are designated as QC/QA records and insuring their deposition into the records system. The PARIS evaluation QC/QA program manager will be responsible for periodically monitoring the implementation of the records system.

Organizations providing support to the PARIS evaluation will be responsible for the QC/QA records generated in the performance of their evaluation tasks. Upon task completion, original QC/QA records from that task will be tumed over to the ORNL principal investigator for entry into the QC/QA records system.

\subsection{Audits and Surveillances}

To verify compliance with (and the effectiveness of) the PARIS evaluation QC/QA program, the independent evaluator will establish a program for planning, scheduling, and reporting of QC/QA audits and surveillances. The program will provide for the reporting and review of audit and surveillance results by appropriate levels of evaluation supervision and management.

The PARIS evaluation QC/QA program manager will be responsible for preparing an audit and surveillance schedule. He will contact the organization being scheduled for an audit or surveillance to arrange a mutually agreeable date for the audit or surveillance, and prepare and transmit a written notification of the impending audit or surveillance. The QC/QA program manager will be responsible for selecting the audit or surveillance team, designating its leader, and describing the areas to be covered in the audit or surveillance. The team, under the direction of the team leader, will be responsible for reviewing the applicable quality requirements and preparing a checklist to be followed during the actual audit or surveillance. Audits and surveillances will be performed, in accordance with written procedures or checklists, by appropriately trained personnel having no direct responsibilities in the area audited or surveiled. Audits and surveillances will be conducted by the QC/QA program manager, a QC/QA specialist, 
or trained personnel from the independent evaluator. Audit and surveillance results will be reviewed with the evaluation study leader responsible for the area audited or surveiled. Audit and surveillance results will be documented and reported to the study leader responsible for the area audited or surveiled.

A report detailing the findings will be provided to the ORNL principal investigator. The evaluation QC/QA program manager will prepare a formal cover letter on the audit or surveillance and transmit it through the appropriate channels. The complete report and requests for corrective action will be part of this transmittal. The QC/QA program manger will be responsible for the audit/surveillance activity to ensure that the required responses are provided, evaluated, and approved and that corrective actions have been implemented. The QC/QA program manager will maintain an audit/surveillance log and an audit/surveillance file for each audit or surveillance.

\section{BIBLIOGRAPHY}

The following documents were consulted during the preparation of the Data Management and QC/QA Plans:

Booz-Allen \& Hamilton (1996). Guidelines for evaluation of FHWA ITS field tests, Draft.

Booz-Allen \& Hamilton (1995). Southwest electronic one-stop shopping field operational test. Motor carrier individual test plan.

Carter, R. J. (1997). PARIS phase I evaluation - Individual evaluation test plans, ORNL/TM13364. ORNL: Oak Ridge, TN.

City of Johnson City (1994). ITS work plan, the Johnson City med/tech corridor, Phase I.

Concord Associates, Inc. (1996). Detailed test plan for evaluating user acceptance of the Atlanta driver advisory system (ADAS).

Georgia Tech Research Institute (1996). Detailed test plan for evaluating system performance of the ADAS.

Lockheed Martin Energy Systems, Incorporated (1995). Quality program description Y/OD-15, Revision 2.

MITRE (1993). Generic IVHS operational test evaluation guidelines. 
Northwestern University Transportation Center and Booz-Allen \& Hamilton (1995). Advanced driver and vehicle advisory navigation concept (ADVANCE), Dynamic route guidance - yoked driver study evaluation test plan.

Northwestern University Transportation Center and Booz-Allen \& Hamilton (1995).

ADVANCE, Familiar driver evaluation test plan.

ORNL (1992). HTR - Proteus, QA plan.

ORNL (1991). Advanced neutron source, QA plan.

Raytheon (1996). ITS, Johnson City, Tennessee, PARIS - phase I, Evaluation plan, Revision C.

Science Applications International Corporation (1995). TravTek data base.

Science Applications International Corporation (1993). TravTek evaluation, Orlando test network study, Final detailed test plan.

\section{ACRONYMS AND ABBREVIATIONS}

ADAS Atlanta driver advisory system

ADVANCE advanced driver and vehicle advisory navigation concept

DOT Department of Transportation

FHWA Federal Highway Administration

ITS intelligent transportation systems

ITSA Intelligent Transportation Society of America

IVHS intelligent vehicle/highway systems

$\mathrm{med} /$ tech medical/technology

NWS National Weather Service

ORNL Oak Ridge National Laboratory

PARIS parking and routing information system 


$\begin{array}{ccl} & \text { QA } & \text { quality assurance } \\ \text { - } & \text { QC } & \text { quality control } \\ \text { TN } & \text { Tennessee } \\ \text { VA } & \text { Veterans Administration } \\ \text { VMS } & \text { variable message sign }\end{array}$




\section{INTERNAL DISTRIBUTION}

1 - 5. R. J. Carter

6. M. D. Galloway

7. R. D. Harris

8. H. E. Knee

9. R. C. Mann

10. C. E. Oliver

11. J. C. Schryver

12. R. F. Sincovec
13.

14.

15.

16.

17.

18.

19.

P. F. Spelt

D. R. Tufano

Central Research Library

CSMD Reports Office

Document Reference Section

Laboratory Records-RC

ORNL Patent Office

\section{EXTERNAL DISTRIBUTION}

20. David E. Castle, Wilbur Smith Associates, 1301 Gervais Street, Fifteenth Floor, Columbia, SC 29201-3356

21 - 23. Kevin Doran, Raytheon Company, 100 Vance Tank Road, Bristol, TN 37620-5698

24. Robert D. James, Center for Transportation Research, Virginia Tech, 1700 Kraft Drive, Suite 200, Blacksburg, VA 24601-0536

25 - 34 William Tate, Raytheon Company, 100 Vance Tank Road, Bristol, TN 37620-5698

35 - 36. Office of Scientific and Technical Information, P. O. Box 62, Oak Ridge, TN 37831 


\section{M98054439}

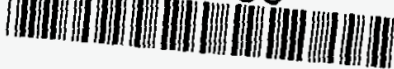

Report Number (14) OR/UL T I - 1336-1

Publ. Date (11)

Sponsor Code $(18) / Z, D O T, X F$

UC Category (19)

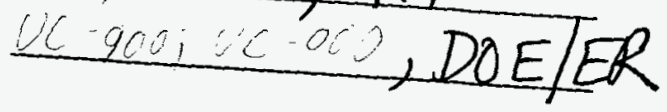

\section{7}

